\title{
CPTAC Cholangiocarcinoma Baseline
}

\section{Form}

National Cancer Institute

\section{Source}

National Cancer Institute. CPTAC Cholangiocarcinoma Baseline Form. NCI Thesaurus.

Code C157528.

Terminology used in support of the data collection efforts of the Clinical Proteomic

Tumor Analysis Consortium (CPTAC) with the focus on Cholang iocarcioma Baseline Form data. 